\title{
SECULARIZACIÓN SOCIAL Y MÉTODOS ACTIVOS PARA LA CATEQUESIS ESCOLAR EN EL FRANQUISMO (1939-1975): PROBLEMAS Y EFECTOS DE UNA TRANSFERENCIA DE PRAXIS EDUCATIVA
}

\section{Social secularization and active methods for school catechesis in the Franco regime (1939-1975). Problems and effects of a transfer of educational praxis}

\author{
Carlos Martínez Valle \\ Universidad Complutense de Madrid \\ Correo-e: carloso3@pdi.ucm.es
}

Rcepción: 5 de agosto de 20I5. Envío a informantes: is de agosto de 2015.

Fecha de aceptación definitiva: 7 de octubre de 2015.

Resumen: El artículo estudia los debates sobre la transferencia educativa de métodos activos a la catequesis escolar impulsados por la secularización social durante la dictadura franquista. Aunque las propuestas partieron del establishment académico que citaba autores escolanovistas, la secularización de la universidad y la diferenciación funcional de la catequesis, la transformación paulatina de las praxis y la dependencia de los puntos de partida y la presión sobre la pastoral social fomentaron la adopción de los métodos de esta última, en particular, la Revisión de vida. La prevalencia de ésta explicaría que los requerimientos del método fuesen en paralelo con las doctrinas del Vaticano II, mostrando la capacidad de la praxis para conformar las ideas. Pero la Revisión de vida y los métodos activos no solo fomentarían una antropología secularizadora, lo que era contradictorio con el propósito inicial, también llevarían al compromiso social y el cuestionamiento de la misma catequesis escolar.

Palabras Clave: Secularización social; catequesis escolar; métodos activos; revisión de vida; pastoral social; franquismo. 
Aвstract: The article studies the debates about the educational transfer of active educational methods to school catechesis fueled by social secularization during the Franco dictatorship. It was the educational academic establishment that begun to propose active methods for the catechesis, quoting progressive educational authors. However, university secularization and catechesis specialization, gradual transformation of the praxis, socio-cultural path dependence and social pressure on social pastoral led to the adoption of the active methods of the latter, particularly the Révision de vie. The extension of this method could explain that some of the changes in, mainly the reading of, the $2^{\text {nd }}$ Vatican matched the requirements of the method, hypothesizing the ability of practices to change ideas. However, the Révision de vie not only fostered a secularizing anthropology, which was contradictory with the original catechetical purpose, but led their adherents to social compromise and to questioning school catechesis itself.

KEY WORDS: Social secularization; school catechesis; active school methods; Révision de vie; Social pastoral; Franco dictatorship.

Triunfante una revolución por la audacia o la violencia, necesita conquistar a las masas espiritualmente, inculcándoles las nuevas ideas para consolidar la revolución. Por eso, en la bandera de todos los partidos políticos hay siempre una preocupación por la acción educativa acorde con su ideología política.

Juan Zaragüeta, Pedagogía Fundamental.

\section{La asignatura de religión y los métodos activos}

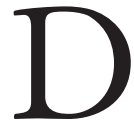

URANTE LA DICTADURA FRANQUISTA (I939-I975) y tras un período de prohibición, Dewey, considerado uno de los teóricos más importantes de los «métodos activos» (en adelante: MA), fue citado progresivamente en obras relacionadas con la enseñanza de la religión, aunque se le acusase de intentar «erradicar la idea del espíritu» ${ }^{\mathrm{I}}$. Este interés por la renovación metodológica es aún más sorprendente porque la enseñanza de la religión impuesta por la coalición entre Iglesia católica y Falangismo era, aun con las características de otras materias escolares, como la designaban los autores que se ocupaban de esta asignatura, una catequesis confesional y proselitista.

Durante el período, los catequistas tuvieron diferentes referencias para los MA, entre otros: los métodos escolanovistas, los de la pastoral social católica y las fórmulas educativas populares latinoamericanas. Así, el artículo se enmarca en los debates sobre el «redescubrimiento» y la adopción de las ideas de la Escuela Nueva en este período histórico². Empero, el significado de «activismo» cambia con

\footnotetext{
Galino, M.: «Prólogo». «Estudio de los pedagogos españoles contemporáneos», en Hovre, F.: Pensadores pedagógicos contemporáneos, Madrid, Fax, 1951.

2 Pozo, María M. y Braster, Sjaak: «El movimiento de la Escuela Nueva en la España franquista», Revista Brasileira da Historia da Educação, I2, 3 (30) (2012), pp. I5-44.
} 
SECULARIZACIÓN SOCIAL Y MÉTODOS ACTIVOS PARA LA CATEQUESIS ESCOLAR EN EL FRANQUISMO (I939-I975): PROBLEMAS Y EFECTOS ...

CARLOS MARTÍNEZ VALLE

cada autor, en un rango que va desde el diálogo en clase al método de proyectos, lo que dificulta el análisis. Además, las transformaciones discursivas tratadas aquí no se aceptan unánimemente. Al final del período muchos catequistas continúan manteniendo que la teología sistemática debe determinar la transmisión de contenidos religiosos 3 .

Los usos discursivos de los MA en la catequesis escolar conectan cuestiones de la transferencia educativa, la historia intelectual y la transformación de la praxis educativa. Primero, el artículo atiende a las condiciones de adopción de una ideología educativa contraria a la cultura (educativa) española resultante de la prevalencia tradicional del catolicismo. Su imagen del ser humano y la consecuente concepción de la educación como una conversación produjo la preterición de la didáctica, en particular los $\mathrm{MA}^{4}$. El artículo investiga también la construcción intelectual de la religión en una «era secular» y sostiene, tercero, que la adopción de prácticas nuevas requiere cambios en las estructuras sociales y creencias claves, y la paulatina transformación de las prácticas anteriores.

Después de analizar a priori algunos problemas para la integración de MA en la catequesis, el artículo sigue sincrónicamente por décadas esta relación, pues praxis y discursos no mostraron puntos de inflexión. Cierra con reflexiones sobre los tres temas citados arriba y apuntes de los incipientes debates sobre la presencia de la catequesis en las escuelas (estatales), un tema que continúa, tras 40 años de democracia, siendo un cleavage fundamental en la educación española.

\section{Una relación problemática: los métodos activos y la religión}

Alberich sostiene que los 200 años de catequesis no han producido una reflexión prolífica sobre sus contenidos y métodos's. El uso de MA en la catequesis supone problemas adicionales a los interdisciplinarios, porque éstos introducen valores y praxis contrarias o diversas a las tradicionales de la catequesis. Los MA presuponen que los niños aprenden al hacer cosas, mientras que, por su naturaleza, gran parte de la religión, en particular el dogma, contradice la experiencia sensible. La revelación funda el poder magisterial de la Iglesia, haciendo necesaria la «heteroformación» frente a la «autoformación».

El activismo es también problemático para los catequistas, porque muchos MA propugnan una moral formal o procedimental, al rechazar morales exógenas impuestas y propugnar la autorregulación de los alumnos, introduciendo lo que muchos religiosos consideran un relativismo moral, por lo que su introducción en la catequesis podría ser, como en el anterior aspecto, contraproducente.

Alberich, Emilio: La catequesis en la Iglesia, Madrid, ccs, I99I. Montero, F.: «La iglesia dividida», en Ortiz, M. y González, D. (eds.): De la cruzada al desenganche: la Iglesia española entre el Franquismo y la Transisión, Madrid, Sílex, 20II, pp. 5I-76.

4 Colom, Antonio y Rincón, Juan: «Epistemología neoidealista y fracaso fundacional del saber educativo", Teoría de la Educación, 16 (2004), pp. 19-47.

Alberich, E.: «Catequética», en Pedrosa, V. M. (ed.): Nuevo Diccionario de Catequesis, Madrid, San Pablo, I999, pp. 4II-4I6. 
Los ma más consistentes, tercero, implican la producción de cosas y la pregunta es ¿̇ «qué» se puede producir para aprender la religión? Los catequistas dan respuestas dispares. Pero desde un punto de vista interno, el de los creyentes, la liturgia y el trabajo y vida comunitarios no son solo instrumentos para el estudio de la religión ni aspectos marginales en una religión basada en las creencias, sino actividades centrales en la afirmación performativa de la fe y, así, instrumentos activos, pues restablecen el vínculo (re-ligare) con Dios y la comunidad, conteniendo la re-ligo ${ }^{6}$. Así, los catequistas distinguen entre la pastoral de la palabra, de la liturgia y la social. Desde una perspectiva externa, si la secularización es producto de la socialización y la pérdida de la comunidad y la religión un recurso comunitario, la catequesis debería reconstruir la comunidad con la liturgia y el trabajo comunitario, pero éstos son ámbitos distintos de la pastoral de la palabra, base tradicional de la catequesis ${ }^{7}$.

Además, la necesidad, tercero, que sienten los catequistas de un cambio en los métodos de enseñanza apunta a un distanciamiento de los estudiantes a la religión, que ya no es universalmente conocida y enseñada por el entorno. Implica una aceptación tácita de la existencia de diversas formas de descreencia y la necesidad de métodos de enseñanza convincentes para quienes nunca vivieron un universo religioso ${ }^{8}$. La secularización social de la sociedad española, «apostasía de las masas», consolidada a pesar de la represión e imposición durante el período9, forzó a los catequistas españoles a buscar métodos más participativos, abarcantes y adaptados a la psicología infantil. La búsqueda de ma para la catequesis sería un indicador de la secularización sociológica.

Pero en este punto, antes de continuar con los problemas que implica la introducción de métodos activos en la catequesis, es necesario un pequeño excurso que diferencie entre los diversos significados de la secularización para afinar el análisis de la historia intelectual y la transferencia educativa. Parte de la literatura mantiene que la diferenciación social-funcional y la consecuente racionalización, centrales en la modernización, separan y hacen autónomos de la religión a otros subsistemas sociales, conduciendo a la reclusión de ésta a la esfera privada y la disminución de la importancia de sus postulados y organizaciones ${ }^{10}$.

6 Boyer, Pascal: Religion Explained, New York, Basic Books, 20oI. Harpur, Tom: The Pagan Christ: Recovering the Lost Light, Toronto, Thomas Allen, 2004.

Wilson, Bryan: «Religion as a Community Resource», Perspectives on Culture and Society, I (I988), pp. 8I-IOO.

8 TAYlor, Charles: A Secular Age, Harvard, Harvard University Press, 2007.

9 PÉrez-Agote, Alfonso: «El proceso de secularización en la sociedad española», Revista CI$D O B, 77$ (2007), pp. 65-82.

1o Luhmann, Niklas: Die Gesellschaft der Gesellschaft, Frankfurt, Suhrkamp, 1997. Casanova, José: Public Religions in the Modern World, Chicago, University of Chicago Press, 1994. TschanNEN, Oliver: «The Secularization Paradigm», Journal for the Scientific Study of Religion, 30 (1991), pp. 395-4I5. Gorski, Philip: «Historicizing the Secularization Debate», American Sociological Review, 65 (2000), pp. I38-167. Dobbelaere, K.: «Assessing Secularization Theory», en Antes, P.; Geertz, A. y Warne, R. (eds.): New Approaches to the Study of Religion, Berlin, De Gruyter, 2004, pp. 229-253. Bruce, Steve: Secularization: In Defence of an Unfashionable Theory, Oxford, Oxford University Press, 20 II. 
SECULARIZACIÓN SOCIAL Y MÉTODOS ACTIVOS PARA LA CATEQUESIS ESCOLAR EN EL FRANQUISMO (I939-I975): PROBLEMAS Y EFECTOS ...

CARLOS MARTÍNEZ VALLE

Empero, los símbolos, ritos y festividades católicos ocuparon el espacio público, incluyendo la escuela, durante toda la dictadura (como lo hacen todavía hoy). El estatus de la Iglesia católica española se mantuvo, incluso después de la Ley 44/1967, "que regula la aplicación del derecho civil a la libertad religiosa», la catequesis escolar, impidiendo su transformación en una asignatura históricocomparativa de la religión. Tampoco la pluralización de las creencias fue la causa de la secularización ${ }^{\text {II }}$.

El paradigma de la modernización explica, también a través de la racionalización, la disminución de la creencia en las enseñanzas religiosas y la distancia a la cultura religiosa, lo que puede llamarse la secularización de la conciencia ${ }^{12}$. Esta secularización de la conciencia o social implica más que incredulidad o descreencia. Significa un cambio en las formas de vivir la religión, porque la secularización hace de ésta una opción entre otras ${ }^{13}$. Mucho más, la secularización de la conciencia implica un cambio de concepción del mundo. En particular, la transformación de las concepciones antropológicas subyacentes. Centrándose en el mundo, la secularización sustituye experiencias y horizontes de realización o plenitud trascendentes por otros inmanentes. Cambia un ser humano que se realiza a través de la trascendencia y la contemplación de Dios, por otro activo que manifiesta sus poderes inmanentes a través de la acción y la producción de sí mismo y del mundo ${ }^{14}$. En lugar de concebir una educación guiada a la virtud por las normas y modelos de la perfección, el objetivo de muchos MAs es, siguiendo a menudo ideas evolucionistas, conformar una persona integrada, socialmente adaptable a través de la resolución de problemas ${ }^{15}$. Así, la adopción de ma en la catequesis podría ser antinómica, pues implicaría adoptar un instrumento que fomentaría una antropología secularizante.

\section{Tras la Guerra: fundamentalismo católico y fascismo}

Las guerras de la cultura y las luchas por la escuela (la secularización social y de la escuela) fueron factores centrales de la Guerra Civil (1936-1939). Basándose en la condena explícita del naturalismo y el optimismo antropológico de la Divini Illius Magistri (\#59 y ss.), el integrismo católico condenó la escuela nueva y los MA en diferentes congresos catequéticos a partir de $1926^{16}$.

Aunque la literatura debate aún el grado de concordancia política entre Falange y el integrismo católico, ambos compartían similares antropologías, lo que

"Como suponen Norris, Pippa e Inglehart, Ronald: Sacred and Secular: Religion and Politics Worldwide, Cambridge, Cambridge University Press, 2004.

12 Tschannen: op. cit. Pérez-Agote: op. cit.

13 Tschanen: op. cit. TAYlor: op. cit.

14 TAYLOR: op. cit.

is Bernstorff, Florian: Darwin, Darwinismus und Moralpädagogik, Kempten, Linkhardt, 2009.

${ }_{16}$ Viñao, Antonio: Escuela para todos, Madrid, Marcial Pons, 2004. MonTERo, Feliciano: Propaganda católica y educación popular en la España de la Restauración, Tours, l'Université de Tours, I988. 
SECULARIZACIÓN SOCIAL Y MÉTODOS ACTIVOS PARA LA CATEQUESIS ESCOLAR EN EL FRANQUISMO (I939-I975): PROBLEMAS Y EFECTOS ...

CARLOS MARTÍNEZ VALLE

permitió una coalición de discurso entre ambos ${ }^{17}$. Los integristas subrayaban una naturaleza humana malvada, caída por el pecado original y hecha de bajos instintos e inmoderados deseos que impiden la salvación y la vida social (servo arbitrio). El fascismo también mantuvo que la codicia estaba detrás de la política redistributiva de la República que habría provocado la guerra. Política y educación debían frenar los instintos y crear hábitos de contención, imponiendo la abnegación por el bien de patria e Iglesia. Como ejemplo de todo un lenguaje ${ }^{18}$, la humillación y mortificación centran la Pedagogía de la lucha ascética de García Hoz (194I), que considera la Guerra Civil y la represión instrumentos educativos divinos para racionalizar las desordenadas pasiones de los españoles ${ }^{19}$. Renuncia y contención continuaron siendo centrales en sus propuestas educativas ${ }^{20}$.

Romero Marín, catedrático de Pedagogía, diagnosticó en El Método Activo (1960) el rechazo del activismo en la dictadura. A pesar de sus prestigiosos proponentes, los MA no habrían podido superar la idea de la necesidad de una autoridad fuerte para inculcar la racionalidad en los niños, inherente a una tradición educativa basada en «una concepción exageradamente pesimista de la naturaleza humana, que solo veía en ella instintos desordenados» ${ }^{21}$.

Sin embargo, el integrismo coexistió ya en los 40 con posiciones más moderadas. El teólogo neoescolástico vasco Zaragüeta (1883-1974) estudió con Mercier y desarrolló su carrera antes de la guerra. Tusquets (190I-I998) fue un sacerdote catalán, informante de los fascistas, malsín y catedrático de Pedagogía General en Barcelona. Fundó Formación catequística y Orientación catequética, revistas fundamentales del campo. Ambos son conscientes de los retos de la secularización: la sociedad moderna ha perdido su unanimidad religiosa y escepticismo o indiferencia definen el nuevo contexto social.

Sus obras ejemplifican los problemas y límites (por los filtros intelectuales del sistema) a la adopción de la idea ajena de los MA o, en términos neoinstitucionistas, de ese mito educativo racionalizado ${ }^{22}$. Zaragüeta considera la fe una facultad cognitiva; la religión un sistema de verdades trascendentales y ayudas sobrenaturales; la liturgia un sacramento de adoración y gracia, y la comunidad una manifestación residual. Mantiene una concepción dogmático-sacramental de la religión, afirmando que la catequesis significa hacer que los estudiantes entiendan y crean unos enunciados hipotéticos, lo que requiere distinguir entre

${ }_{17}$ Morente, F.: «Los fascismos europeos y la política educativa del franquismo», Historia de la Educación, 24 (2005), pp. 179-204.

18 Otros autores que compartirían este lenguaje serían, p. e.: Guerrero, Eustaquio: Fundamentos de pedagogía cristiana, Madrid, Razón y fe, I959. Ruiz, Manuel: Hacia una pedagogía de la obediencia cristiana, Madrid, Studium, 1968. LeIros, Sara: Pedagogía hispano-cristiana en su dimensión espiritual, Madrid, Mundo Negro, 1973.

19 García-Hoz, Víctor: Pedagogía de la lucha ascética, Madrid, s. n., I94I.

20 García-Hoz, Víctor: La tarea profunda de educar, Madrid, Rialp, 1962, con reimpresiones hasta I979.

${ }_{21}$ Romero Marín, Anselmo: El Método Activo de la Enseñanza, Madrid, Bolañós y Aguilar, 1960.

22 Meyer, John y Rowan, Brian: «Institutionalized Organizations: Formal Structure as Myth and Ceremony", American Journal of Sociology, 83, 2 (1977), pp. 340-363. 
SECULARIZACIÓN SOCIAL Y MÉTODOS ACTIVOS PARA LA CATEQUESIS ESCOLAR EN EL FRANQUISMO (1939-I975): PROBLEMAS Y EFECTOS ...

CARLOS MARTÍNEZ VALLE

profesores y neófitos, la «heteroformación». Los instrumentos didácticos que propone traducen sus concepciones: la naturaleza y monumentos religiosos que invitan a conocer y alabar al señor; libros y grabados de personajes bíblicos que fomentan el aprendizaje vicario de la ética. Tusquets acepta que la psicología infantil va de las sensaciones concretas y artefactos construidos a los símbolos y teoría abstractos, pero subraya que la vida religiosa consiste en trascender el mundo físico.

Ambos afirman distinguirse de Stieglitz, Göttler y el método de Munich y consideran que los MA pueden ser provechosos para enseñar religión ${ }^{23}$. Tusquets incluso los critica por desconocer la experiencia infantil e impedir expresar libre y personalmente lo que aprenden. Considera que los centros de interés de Decroly o el Método de Dewey (sic) son compatibles y añaden al Stieglitz un carácter social necesario para una verdadera vida religiosa en el catolicismo. Sostiene que el método de Dewey (sic) consiste en «proponer a los niños la realización de una obra colectiva y, una vez aceptada, proyectarla. Trabajando en ella, los alumnos buscan y adquieren el conocimiento de la lección». Zaragüeta define los ma no como un procedimiento heurístico o intelectual, sino un método basado en el «grado más alto de iniciativa de los alumnos que, estimulados y orientados por el profesor, exploran y descubren por su propio esfuerzo el horizonte de la disciplina». Ambos consideran ma todas las formas de aprendizaje en las que los estudiantes no son meros receptores pasivos.

Ambos critican, como sus predecesores, la dificultad de cumplir el temario y mantener la disciplina con los MA. Así, aunque Tusquets alabe el «Método de Dewey» por su carácter social, divide, siguiendo la tradición jesuita, la clase en decurias jerárquicamente organizadas y concurrentes entre sí. La disciplina a través de la competencia contradice muchas propuestas escolanovistas.

Pero el principal problema para ambos es que, como las verdades trascendentes no son accesibles por la experiencia y sólo se revelaron a la Iglesia, ésta debe ejercer su función magisterial. Teniendo en cuenta la naturaleza y luces humanas, la catequesis debe usar la heteroinstrucción y la educación vicaria tradicional en la Iglesia. Sin embargo, la aceptación de Tusquests de que los estudiantes hablen libremente manifiesta ya un enfoque más laxo, pues uno de los problemas de la enseñanza religiosa es la precisa terminología teológica, que hace que el habla libre pueda conducir a significados heterodoxos ${ }^{24}$.

Aunque, en La religión explicada a los mayorcitos (1946), Tusquets cita a autores escolanovistas, funda su didáctica en un instrumento de la pastoral social, que encajaría en la «psicología de los jóvenes», el círculo de estudio. Cada unidad se basa en un debate sobre posibles experiencias del estudiante, pero dirigido por reflexiones iniciales, conclusiones, recapitulaciones y propuestas de acción ejemplificadas en las vidas de santos. Los dispositivos

23 Zaragüeta, Juan: Pedagogía de la religión, Madrid, Espasa-Calpe, i94I. Tusquets, Joan: Pedagogía catequística para seglares, Barcelona, Lumen, 1944.

24 Ibidem. 
SECULARIZACIÓN SOCIAL Y MÉTODOS ACTIVOS PARA LA CATEQUESIS ESCOLAR EN EL FRANQUISMO (1939-1975): PROBLEMAS Y EFECTOS ...

CARLOS MARTÍNEZ VALLE

didácticos incluyen también, como el clásico catecismo de Llorente, imágenes y gráficos ${ }^{25}$.

Por lo tanto, Tusquets y Zaragüeta consideran necesaria la heteroinstrucción, proponen actividades de mera naturaleza intelectual que mantienen los límites de las taxonomías disciplinarias y no tienen aspectos productivos.

\section{Los 50}

Menciones a los MA reaparecen en el discurso educativo español gradualmente después de la caída del fascismo y la «apertura» del régimen; con la transformación del régimen totalitario en uno autoritario-tecnocrático a principios de los $50^{26}$. Los acuerdos España-Usa (1953), con el liberalismo ahora como aliado contra el comunismo, permitieron la ambivalente y moderada atención prestada a Dewey, «ese etnotípico educador norteamericano» ${ }^{27}$. Las traducciones de Planchard, Hovre y Redden y Ryan establecieron una evaluación de la Escuela Nueva que, aunque seguía la Divini Illus Magistri, aceptaba algunos aspectos del activismo con fines religiosos ${ }^{28}$.

Con el aperturismo, el establishment académico de la educación eligió las mismas opciones filosóficas predominantes en la universidad en la preguerra: Neotomismo, Fenomenología Hermenéutica, Vitalismo-Existencialismo (Bergson, Jasper, Marcel), Axiología, Neoidealismo, Historicismo y Personalismo ${ }^{29}$. Esta aparente diversidad estaba moderada por principios comunes que filtraban y regulaban su aceptación ${ }^{30}$. La antropología básica que determinaba el rango de las opciones era la idea de un humano racional y libre pero que precisa ser educado, i. e., liberado de bajos instintos y pasiones a través de modelos, normas y valores trascendentes, para realizarse en la virtud y la sabiduría, alcanzando la felicidad-beatitudo. La contemplación, más que la acción, sería el objetivo real de la humanidad. Como el libre albedrío implica contingencia, la educación sería una «práctica moral deliberativa», un arte o conversación casuística dirigida

${ }_{25}$ Tusquets, Joan: La religión explicada a los mayorcitos, Barcelona, Lumen, 1946. Llorente,

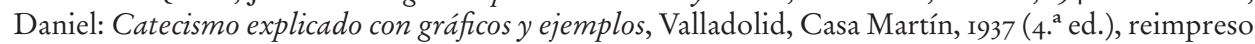
hasta mediados de los años 60.

26 Linz, Juan José: Totalitäre und autoritäre Regime, Postdam, Weltrends, 2009.

27 Iriarte, Joaquín: «Una filosofía con sede en los rascacielos», Razón y Fé, 6, 713 (1957), pp. 549-560.

${ }_{28}$ Planchard, Emile: La pedagogía contemporánea, Madrid, Rialp, 1949. Hovre, Francis: Pensadores pedagógicos contemporáneos, Madrid, fax, I95I. Redden, J. D. y Ryan, F. A.: Filosofía católica de la educación, Madrid, Morata, I96I.

29 Fermoso, Paciano: Filosofía de la educación, Madrid, Bibliográfica Española, 1970. ViLAnou, C.: «Pensamiento y discursos pedagógicos en España (I898-1940)», en Berrio, J. (ed.): La educación en España a examen, Zaragoza, Fernando el Católico, 1999, pp. 19-57. Orden, R.: «La formación de una Escuela de Filosofía», en López-Ríos, S. (ed.): La Facultad de Filosofía y Letras de Madrid en la Segunda República, Madrid, secc, 2008, pp. 2I2-223. Colom y Rincón: op. cit.

30 Schriewer, Juergen y MarTínez, Carlos: World-Level Ideology or Nation-Specific System reflection?, Lisboa, Educa, 2003. 
SECULARIZACIÓN SOCIAL Y MÉTODOS ACTIVOS PARA LA CATEQUESIS ESCOLAR EN EL FRANQUISMO (1939-I975): PROBLEMAS Y EFECTOS ...

CARLOS MARTÍNEZ VALLE

teleológicamente por fines-valores exógenos, que no puede ser totalmente comprendida y dirigida por la ciencia, aceptada sólo como conocimiento subsidiario ${ }^{31}$. La educación se concibe pues como una doctrina, una praxis guiada por axiomas religiosos o filosóficos ${ }^{32}$. Este consenso determina la forma en que fueron comprendidos los ma durante este período.

En 1950, el cuarto Congreso Nacional de Catecismo hizo hincapié en la necesidad de buscar métodos más eficaces. Ibáñez Martín, ministro de Educación Nacional, tras ratificar el poder magisterial de la Iglesia y el papel subsidiario del Estado, aboga por nuevos métodos educativos en la catequesis. Sostiene que la religión no debe ser concebida como otra asignatura dirigida a la adquisición formal del conocimiento, sino utilizar otros métodos para activar habilidades y sentimientos específicos. Su discurso parece ser un rechazo del viejo método hermenéutico, pero no propone ninguno alternativo y sí una educación magistrocéntrica $^{33}$. Iguales deseos de cambio metodológico y falta de propuestas (salvo vagas menciones a la importancia de la experiencia) aparecen en otras publicaciones de los $50^{34}$.

A fines de los 40, principios de los 50, la Revista Española de Pedagogía publicó una serie de artículos sobre didácticas específicas, iniciados por García-Hoz y Tusquets, que ahora aceptaban el positivismo, la filosofía lógica o la pedagogía hebartiana como instrumentos auxiliares para la aplicación de los principios trascendentales a la práctica. Tusquets distingue tres métodos de enseñanza: analítico, integral y social, e incluye los activos en los métodos sociales. La principal virtud de los MA sería que permitirían trabajar cooperativamente y establecer objetivos no completamente egoístas, sino sociales y personales, al mismo tiempo. En definitiva, las propuestas no solo apuntaban al estudio de la religión, sino a un diagnóstico tradicional de los males de la sociedad española que achacaba, entre otros, al individualismo excesivo, su inmoralidad y retraso ${ }^{35}$. También el objetivo fundamental de la reforma propuesta por García-Hoz era «inculcar en las almas de los alumnos los ideales de la cooperación, el acuerdo social o la comprensión, la ayuda mutua y la buena voluntad». García-Hoz propone para las Ciencias Sociales un cuestionario destinado a fomentar la «participación

${ }_{31}$ Tusquets: 1951, op. cit. Damseaux, Eugenio y Solana, Ezequiel: Historia de la Pedagogía, Madrid, Escuela Española, 1967. Fermoso, Paciano: Filosofía de la educación, Madrid, Bibliográfica Española, I970.

32 Pacios, Arsenio: Filosofía de la educación, Madrid, Orbe, 1947. Galino, María: Cuestiones de filosofía de la educación, Madrid, Bolaños y Aguilar, 1952. Palmés, F.: «Prólogo», en Barbey, L.: Pedagogía cristiana y experimental, Barcelona, Subirana, 1953. Galino, M.: «Introducción», en Redden, J. D. y Ryan, F. A.: i96I, op. cit. Millán Puelles, Antonio: La función subsidiaria del Estado, Madrid, Magisterio Español, 1963, entre otros.

33 IBÁÑ̃z-Martín, José: «Discurso en el Congreso Nacional del Catecismo», Revista Nacional de Educación, 98 (1950), pp. 79-95.

34 Alonso, Práxedes: Pedagogía catequística, Barcelona, Vilamala, 3. ${ }^{a}$ ed., I957. GIL, A.: «Didáctica», en Ibidem, Estudios pedagógicos modernos, Málaga, Denis, 1957.

35 TusqueTs, Joan: «La función catequística del maestro», Revista Española de Pedagogía, 36 (I95I), pp. 20-46. 
SECULARIZACIÓN SOCIAL Y MÉTODOS ACTIVOS PARA LA CATEQUESIS ESCOLAR EN EL FRANQUISMO (I939-I975): PROBLEMAS Y EFECTOS ...

CARLOS MARTÍNEZ VALLE

activa» y la «conversación de los alumnos», con las «que el profesor también puede aprender» y que muestra la infiltración de la religión en las otras asignaturas y el interés en la piedad popular como instrumento catequético. Las últimas preguntas tratan las prácticas y asociaciones piadosas de los alumnos de las comunidades, como misas, ritos, fiestas, peregrinaciones, hermandades, etc. ${ }^{36}$.

Incluso la mera consideración discursiva de los MA, requería una rehabilitación previa que los «cristianizase». Esto se realiza a través de genealogías de proponentes de los MA, que eran tanto instrumentos epistemológicos como argumentos de autoridad. Las genealogías (Platón, Tomás de Aquino [De Magistro], Bacon, la Ratio Studiorum o Pestalozzi) reclaman su ortodoxia antes de ser heréticamente radicalizadas por Rousseau y el escolanovismo. En un caso claro de intelección con los marcos mentales que poseían, los estamentos académicos filtran la nueva información y relacionan, desde Llorente, el activismo con la mayéutica o «método intuitivo» ${ }^{37}$. En Francia, también, el trabajo de Colomb, mencionado abajo, fue criticado por parte del clero como platonizante ${ }^{38}$. Empero, la mayéutica implica una visión restringida de la labor educativa, de los alumnos y de la didáctica en la que los estudiantes solo reflexionan, excluyendo el trabajo directo (manual) y la producción. Esta identificación hace cuestionar si nuestros autores fueron más allá del Método Stieglitz que «proponía la presentación intuitiva del tema, la explicación y la aplicación a la vida o estimulación ${ }^{39}$.

Los ma chocaron con los presupuestos básicos que formaban el filtro de recepción en torno a las ideas y valores trascendentes y la epistemología (intereses y voluntades, inductivismo, el valor de la experiencia). García-Hoz señala a algunos de ellos, incluso en obras posteriores. En ellos, tras rechazar metodologías inductivas, apunta al problema: «la noción de causa última ha perdido su fuerza», mientras que el positivismo hace de la sociedad el juez para resolver problemas educativos y determinar sus objetivos y procesos $^{40}$.

\section{Los 6o. La diferenciación funcional y política de la catequesis y la Iglesia}

Nasci em um tempo em que a maioria dos jovens havia perdido a crença em Deus, pela mesma razão que os seus maiores a haviam tido - sem saber por quê. O Livro do Desassossego. Fernando Pessoa.

Los progresivos cambios sociodemográficos, urbanización e industrialización (socialización) y las transformaciones culturales relacionadas (secularización)

36 García-Hoz, Víctor: Elementos para un programa de enseñanzas sociales, Madrid, Revista Española de Pedagogía, 1948.

37 Romero: op. cit. Tusquets: 1951, op. cit. Llorente, Daniel: Tratado elemental de pedagogía catequística, Valladolid, Martín Sánchez, I928.

${ }_{38}$ Molinario, Joël: Joseph Colomb et l'affaire du catéchisme progressif, Paris, DDB, 2010.

39 Jedin, Hubert et al. (eds.): The Church in the Modern Age, London, Burns and Oates, I98I.

40 García-Hoz, Víctor: Principios de pedagogía sistemática, Madrid, Rialp, I96o. Pacios, Arsenio: Filosofía de la educación, Madrid, Orbe, 1947. 
SECULARIZACIÓN SOCIAL Y MÉTODOS ACTIVOS PARA LA CATEQUESIS ESCOLAR EN EL FRANQUISMO (1939-I975): PROBLEMAS Y EFECTOS ...

CARLOS MARTÍNEZ VALLE

empujaron al establishment eclesial y académico a buscar nuevos conceptos y métodos didácticos para mantener la obediencia a la Iglesia y el franquismo ${ }^{4}$. Durante los 60 hay un redescubrimiento gradual de las ideas escolanovistas ${ }^{42}$.

Otro cambio ideológico que influyó en el discurso académico fue el aggiornamento y el Concilio Vaticano II (1959-1965). Desde 1967, la Comisión Episcopal de Enseñanza celebra reuniones periódicas para proponer nuevas orientaciones y fórmulas, lo que apunta a una progresiva diferenciación funcional de la catequética. El discurso introductorio del presidente de la Comisión Episcopal de Enseñanza menciona la influencia del Vaticano II (Presbyterorum Ordinis, 22; Gaudium et Spes, I-II; 2I-22, i. a.) en la organización de las primeras Jornadas de 1966. Las presentaciones mencionan algunas razones de la secularización: la capacidad de los humanos para transformar el mundo y hacerlo seguro ${ }^{43}$, el pensamiento científico, el pluralismo cultural y una «cultura de hacer públicas las deliberaciones, incluso las de la Iglesia» y sus efectos: el rechazo de la enseñanza de la religión por los alumnos ${ }^{44}$. Sin embargo, las ideas propuestas por la jerarquía eclesial en las ponencias del encuentro son tradicionales: las referencias (Manjón, Llorente, el cardenal Newman o Acerbo Nimis), jerarquía (el obispo como único pastor pleno), concepción del cristianismo (no una filosofía o sistema de vida, sino una fe dogmática) y antropología (abnegación). Proponen una catequesis de la «renovación kerigmática» que, centrada en anunciar la salvación de Cristo, requiere un método magistrocéntrico. Aunque algunas pidan adaptar el mensaje al hombre moderno, proponen, coherentes con el enfoque kerigmático, una mezcla de historia para comprender el misterio y de apelación a la «facultades inferiores» (sentidos, sentimientos, sensibilidad, estética) para que los alumnos se «den cuenta» de la religión. Además, consideran la liturgia como un «lenguaje» específico para la transmisión de la verdad. Otras avistan un método en el que el «mismo alumno a través de un diálogo piense, exprese y comunique su fe» ${ }^{45}$.

Los grupos de trabajo de las jornadas tienen una perspectiva más clara y diferente. Son críticos con la concepción jurídico-dogmática de la religión de la jerarquía, su reducción de la moral a la contención sexual o el carácter académico de una asignatura basada en la memorización, separada de aspectos emocionales y volitivos, la vida, la liturgia o la Biblia. Mantienen que este academicismo le impide servir como catequesis, para convertir o fortificar la fe de los creyentes. Aunque todavía no hay una acusación directa sobre su responsabilidad en la secularización, algunas presentaciones critican la inactividad de la Iglesia, que delegó en la escuela nacional el trabajo del clero y subrayan la necesidad de la planificación pastoral y la coordinación. Estas son las primeras dudas que hemos encontrado entre los catequistas sobre la conveniencia de una asignatura confesional.

${ }^{4}$ SÁnchez, Fernando: La España del Siglo XX, Madrid, Istmo, 2003.

42 Pozo: op. cit.

43 En línea con Norris e Inglehart: op. cit.

44 I Jornadas Nacionales de Estudios Catequéticos: Por una formación religiosa para nuestro tiempo, Madrid, Marova, 1967.

45 Ibidem. 
Los grupos de trabajo están más cerca del Vaticano II, pues defienden una catequesis conectada con la experiencia, la comunidad y las necesidades antropológicas y sociales. Esta posición no sólo está determinada por la procedencia sociocultural de sus miembros, catequistas de base, en vez de miembros del establishment académico o eclesiástico; también explica por qué eligen y proponen un instrumento catequético determinado y se explica por la acción de este instrumento: la Revisión de vida.

Ésta es un método de educación popular creado por J. Cardijn en los años 20 que propone 3 actividades de grupo interconectadas: ver, juzgar y actuar. Se basa en el análisis conjunto de incidentes vividos por cualquier participante y un juicio y la resolución de actuar del grupo siguiendo una perspectiva evangélica. Se conforma, pues, como un instrumento de reflexión y acción católica que propone una nueva espiritualidad intramundana que engarza el mensaje de Cristo en la vida cotidiana o, también, un método de resolución de problemas siguiendo valores evangélicos. El método, el más democrático y horizontal desarrollado por la pastoral social, tiene sin duda la máxima importancia en la creación de una nueva sensibilidad y conciencia social, la creación de una «catequesis de la experiencia» y seguramente en la convocatoria del Vaticano II.

En España, la jerarquía y Acción Católica (AC) habían fundado la HOAC (Hermandad Obrera de Acción Católica) y la Joc (Juventud Obrera Católica) para el control de los trabajadores católicos ${ }^{46}$. La Revisión de vida se fomentó en estas asociaciones durante los años 60 a través de traducciones y obras de autores españoles, hasta ser aprobada oficialmente por JACE (Juventud de Acción Católica Española) en $1960^{47}$. Su adopción llevó a la progresiva izquierdización y a la participación de éstas en todos los espacios sociales incluida la educación cívica y religiosa, hasta su separación de AC en los primeros $70^{48}$. El método produjo una transformación radical en la teología, objetivos y formas de acción de estas organizaciones y sectores afines, siendo muy relevantes en el proceso de «desenganche» de la Iglesia del régimen ${ }^{49}$. La Revisión de vida muestra claramente cómo los cambios en la práctica transforman ideas y teorías.

\footnotetext{
${ }_{46}$ Martín, Antonio: «Los propagandistas en los primeros años cincuenta», Aportes: Revista de Historia Contemporánea, 20, 57 (2005), pp. 22-35.

47 Marechal, Albert: La Revisión de vida, Barcelona, Nova Terra, I960. Bonduelle, Jourdain: Situación actual de la Revisión de vida, Barcelona, Nova Terra, 1965. GRUpos de Apostolado ObreRO: Al encuentro de Cristo en el otro por la revisión de hechos de vida obrera, Madrid, Estades, 1958. Martínez, Francisco: Principios fundamentales sobre la revisión de vida, Zaragoza, Berit, 1968. Royo, Eugenio: Acción militante y Revisión de vida, Madrid, Popular, 1967. Maraval, Juan: Actividades apostólicas de las religiosas y "revisión de vida», Bilbao, Mensajero, 1970, entre otros.

${ }^{48}$ Fullana, Pere y Montero, Feliciano: «Los modelos educativos juveniles del movimiento católico en España», Revista Historia de la Educación, 22-23 (2003-2004), pp. 33-5I. Domínguez, Javier: Organizaciones obreras cristianas en la oposición al franquismo, Bilbao, Mensajero, 1985.

49 Comisión General de la hoac: Cristianos y revolucionarios, Programa militante de la HOAC, Madrid, HOAC, I979. CARCEL, Vicente: La Iglesia en la España contemporánea (1808-1975), Madrid, Católica, I979. Montero, F.: «La iglesia dividida», en Ortiz, M. y González, D. (eds.): De la cruzada al desenganche: la Iglesia española entre el Franquismo y la Transisión, Madrid, Sílex, 20II, pp. 5I-76.
} 
SECULARIZACIÓN SOCIAL Y MÉTODOS ACTIVOS PARA LA CATEQUESIS ESCOLAR EN EL FRANQUISMO (I939-I975): PROBLEMAS Y EFECTOS ...

\section{6. $\operatorname{Los} 70$}

Las segundas Jornadas, Futuro de la educación y futuro del bombre, consideran las posibilidades y riesgos de la contradictoria Ley General de Educación, que introdujo algunos énfasis en una antropología y métodos activos ${ }^{50}$. Las ponencias critican la catequesis practicada mayoritariamente como apodíctica, especulativa y desconectada de la vida. Aunque algunos autores mencionan a Dewey, las propuestas didácticas provienen también de la pastoral social: le Sillon, un paso intermedio entre los círculos católicos obreros y la Revisión de vida, que consiste en círculos de debate y discusión sobre temas propuestos por los participantes ${ }^{5 \mathrm{I}}$.

En I971, apareció la traducción al español del Manual de Pedagogía Catequética de Colomb, un «clásico de la catequesis», polémico a fines de los 50 en Francia y que se basa en una antropología positiva y activa y el concepto deweyano de experiencia ${ }^{52}$.

Concepciones similares de catequesis de la experiencia se presentaron en las terceras Jornadas de pastoral educativa (1970), La catequesis española frente a la reforma legal y el cambio cultural, que atendían al marco de la nueva ley. Los autores diagnostican la crisis religiosa que surge de la «disolución de las imágenes tradicionales del mundo» y del pluralismo de referencias. La transformación de la catequesis es necesaria pues la religión ha perdido su condición de «evidencia previa incuestionable» $\mathrm{y}$ el medio ambiente no es propicio para los mensajes religiosos, lo que dificulta incluso a los catequistas entender, vivir y manifestar su fe $\mathrm{f}^{53}$.

Muchas ponencias responsabilizan a la Iglesia y las escuelas católicas de la desafección de la gente y de falta de flexibilidad para adaptarse al nuevo mundo. Condenan los obstáculos que ponen a una fe viva y liberadora: el control por la curia de ritos y pensamientos que mantiene al laicado como menor de edad; el mal y rígido gusto estético; y la falta en la escuela religiosa de espíritu cristiano, creatividad intelectual, innovación pedagógica e impulso liberador. Las soluciones para este diagnóstico son el rechazo de cualquier monopolio cultural y moral y el servicio a los pobres en lugar de la alianza con las élites. Proponen también, siguiendo la Perfectae Charitatis, la «desinstitucionalización» de las escuelas católicas y su apertura a la sociedad, creando una juventud cristiana «desviada» de la norma, resistente en la manifestación de su fe y dedicada al cambio social. Esta juventud debe ser educada en la experiencia de la trascendencia, el redescubrimiento de la fe sobrenatural y su conciliación con la razón ${ }^{54}$.

so II Jornadas de Pastoral Educativa: Futuro de la educación y futuro del hombre, Madrid, Bruño, I97I.

sI SAngnier, Marc: Une méthode d'éducation démocratique, Paris, Au Sillon, 1906.

52 Colomb, Joseph: Manual de Catequética, Barcelona, Herder, 1971. Pedrosa, Vicente et al.: Nuevo Diccionario de Catequética, Madrid, San Pablo, I999.

53 III Jornadas de Pastoral Educativa: La catequesis española ante la reforma pedagógica y el cambio cultural, Madrid, Bruño, I97I.

${ }_{54}$ Ibidem. 
Algunas presentaciones abogan por mA (Decroly, Freinet), pero sostienen que si bien, a partir de finales de los 60, parecen ser aceptados generalizadamente, sólo unos pocos autores y maestros (laicos y religiosos por igual) los conocen y aún menos los utilizan, ya que implican mayores cargas de trabajo que los tradicionales. Berrio aclara el significado del activismo escolar: los profesores guían los grupos autoorganizados de estudiantes y rechazando los libros de texto; el conocimiento se adquiere en áreas de contenido, no en las asignaturas tradicionales ${ }^{55}$.

Otros participantes, todos religiosos, defienden la renovación kerigmática (siguiendo el modelo del catecismo católico alemán de i955 que en España se había plasmado en los catecismos escolares de 1963) y el estímulo de las facultades inferiores o un programa que abarca de la animación sociocultural al uso de los centros de interés de los estudiantes. El más elocuente propone una «catequesis de la experiencia», basada en le Sillon y la Revisión de vida: la creación de grupos de discusión que incluyen la documentación, la elección de lecturas, debates, programas y actividades de intervención social para la creación de comunidad. Algunos sostienen que los MA son un desafío para la Iglesia porque implican permitir el acceso de los estudiantes al Evangelio, su cuestionamiento de las ideas tradicionales y la búsqueda de formas más evangélicas y comunitarias de vida, porque la catequesis es imposible sin experiencias de fe y la comunión con el prójimo ${ }^{56}$.

Las últimas propuestas se basan en una antropología positiva que, como Colomb, rechaza la apologética tradicional que justifica a Dios en la necesidad sentida por un débil ser humano de un orden superior y se centran en la realización plena a través de la apertura a una trascendencia bastante intramundana, suavizando el dualismo tradicional de la Iglesia al considerar interdependientes al humano y el mundo a través de la acción del sujeto. El antidualismo es un principio básico en la antropología de la Escuela Nueva (e. g. Dewey).

Las IV Jornadas, «la Educación de la fe en los adolescentes» (1972), muestran una división entre propuestas de renovación kerigmáticas y la de la experiencia. Los proponentes de la renovación kerigmática defienden que el problema metodológico está solventado, pues la catequesis debe basarse en la teología, y condenan la conversión de la liturgia en espectáculos folclóricos. Los proponentes de la «catequesis experiencia» rechazan considerar la religión como asignatura escolar porque la vocación cristiana implica la conciencia social y la creación de la comunidad, que es instrumento y objetivo de la educación activa ${ }^{57}$.

Así, la elección del método está preñada de consecuencias, llevó a la izquierdización de los movimientos sociales que lo adoptaron y en la escuela al cuestionamiento, como en el caso de Colomb ${ }^{58}$, de la presencia de la catequesis en la escuela.

"S Ruiz Berrio, Julio: «Características y orientaciones del movimiento pedagógico actual in La catequesis Española ante la reforma pedagógica y el cambio cultural», en II Jornadas de Pastoral Educativa, op. cit., pp. 7-24.

56 II Jornadas: op. cit.

57 IV Jornadas de Pastoral Educativa: Catequesis hoy, Catequesis de la experiencia, Salamanca, Ediciones San Pío X, I973.

$5^{8}$ Bonato, Graziella: Elogio alla laicità, Mantova, Cittadella, $20 \mathrm{I} 4$. 
SECULARIZACIÓN SOCIAL Y MÉTODOS ACTIVOS PARA LA CATEQUESIS ESCOLAR EN EL FRANQUISMO (1939-I975): PROBLEMAS Y EFECTOS ...

CARLOS MARTÍNEZ VALLE

Elías Yáñez, de la Conferencia Episcopal, sostiene que la catequesis debe ser parte del plan de estudios oficial, mientras que Demetrio González, que defiende una catequesis basada en una combinación de las ideas de renovación pedagógica y pastoral social, sostiene que la escuela no es el lugar para la educación de la fe, independientemente de los acuerdos entre la Santa sede y el Estado españols9.

\section{Conclusiones}

La necesidad de MA en la catequesis escolar comenzó a tratarse en la comunidad académica educativa en los años 40. Hasta finales de los años 60, momento en el que comienzan a implantarse métodos que podrían considerarse activos, los pedagogos los equipararon a cualquiera diferente de la enseñanza frontal, en particular los que atendían a la psicología del estudiante. La progresiva secularización de la sociedad española hizo que la religión dejase de ser transmitida por el entorno obligando a transformar su enseñanza para recrear un universo religioso. La Mater et Magistra, pero fundamentalmente el Vaticano II, en particular por la revisión de las formas de transmisión del depositum fidei, permitió el aggiornamento de los métodos de enseñanza de una manera que se correspondía con las exigencias lógicas de estos MA. La Gaudium et spes (22) o el decreto Unitatis redintegratio (2.6) declararon, distinguiendo la sustancia doctrinal de su formulación, que la «doctrina auténtica» debe ser estudiada y expuesta a través de métodos y formas «modernas, pues el magisterio de la Iglesia es predominantemente pastoral», subrayando su efectividad en la vida de los creyentes $^{60}$.

La correspondencia entre las enseñanzas de la Iglesia y los requisitos y resultados de los MA, en particular la Revisión de vida, es explicable. El estudio demuestra la capacidad de las prácticas de modelar y transformar las ideas, como atestiguan la expansión interrelacionada de la Revisión de vida, el cuestionamiento de la catequesis escolar y la concienciación y práctica social, que reivindicó progresivamente una pastoral social y una religión vivida para los necesitados. El más activo de los métodos fue el más democrático. La extensión de la Revisión de vida podría haber sido instrumental en la convocatoria del Vaticano II o la creación de los movimientos de base católicos que fueron fundamentales para la Transición.

Aunque el establishment académico educativo que trabajó la catequesis escolar citaba la tradición de la escuela progresiva (Dewey, Freinet, Decroly), los catequistas de base adoptaron ma desde la propia tradición social de la Iglesia: la Revisión de vida y los círculos de debate. Esto podría tener varias razones.

59 IV Jornadas: op. cit.

60 Pablo VI. Pastoral Constitution on the church in modern world Gaudium et Spes (1965). Retrieved from: http://www.vatican.va/archive/hist_councils/ii_vatican_council/documents/vat-ii_ cons_19651207_gaudium-et-spes_en.html. Pablo VI. Decree on Ecumenism Unitatis Redintegratio (I964). Retrieved from http://www.vatican.va/archive/hist_councils/ii_vatican_council/documents/ vat-ii_decree_1964II2I_unitatis-redintegratio_en.html. 
SECULARIZACIÓN SOCIAL Y MÉTODOS ACTIVOS PARA LA CATEQUESIS ESCOLAR EN EL FRANQUISMO (1939-1975): PROBLEMAS Y EFECTOS ...

CARLOS MARTÍNEZ VALLE

En primer lugar, muchos españoles no terminaron de comprender los MA escolanovistas. En particular, los catequistas entendieron los MA escolares y la catequesis de la experiencia con sus marcos intelectuales, equiparándolos al platonismo y acusándolos de inmanentismo, al igual que ocurrió en Francia, décadas antes, con el trabajo de Colomb. Se podría interpretar la atención al anuncio del mensaje salvífico (como elemento exógeno al individuo) de la catequesis de la «renovación kerigmática» como una reacción a la nueva catequesis de la experiencia.

La adopción de nuevas prácticas escolares (MA) es más difícil que la recepción de referencias escolanovistas, debido a que la adopción de las nuevas prácticas requiere la transformación progresiva de la praxis preexistente, lo que se ejemplificaría en la lenta transformación de las discusiones de clase a los grupos de debate, le Sillon y la Revisión de vida. Esta transformación es, pues, path dependent. Además, la práctica catequética más cercana y establecida era la pastoral social, no la Escuela Nueva ${ }^{6}$.

La marginación de los ma escolares se produjo también por la secularización y diferenciación funcional de la universidad, que abandonó la catequesis como objeto intelectual, dejándola en manos de la Iglesia y especialmente de catequistas de base que fueron creando foros independientes para su discusión.

Otra razón sería la institucionalización de la catequesis confesional en las escuelas españolas que impidió la pedagogía de la religión. La renovación necesaria procedió de una zona no institucionalizada, donde la secularización del mundo se sentía más acremente: la pastoral social. Tal vez debido a la censura, no hemos encontrado referencias explícitas a los MA de educación popular latinoamericana. Algunas menciones a un desarrollo de «comunidades sociales» en las II Jornadas de Pastoral Educativa (I97I) podrían ser una referencia tanto a la Revisión de vida o los ma de la educación popular latinoamericana ${ }^{62}$.

La secularización y sus manifestaciones conforman la religión, determinando lo que se considera como tal y las formas en que la viven los creyentes. Por otra parte, la secularización y los intentos de la Iglesia de (re)crear un universo religioso implicaba cambios en la consideración y las prácticas de la jerarquía, la fe y el ritual ${ }^{63}$. La Revisión de vida requiere un uso directo cada vez mayor de la Biblia, lo que concuerda con la consideración más abierta y comunitaria del acceso al depositum fidei, de la Iglesia y la vida cristiana del Vaticano II (Dei Verbum n. ${ }^{\circ}$ Io) pues la verdad y la gracia divina serían capaces de vivificar la fe de los devotos (Enchiridion Vaticanum, I, 448). Muy relacionado, se produce también el cambio de tensión de una concepción intelectual de la religión a una vivida, que podría expresarse en un cambio de acento de la fides qua creditur a la fides quae creditur.

${ }_{61}$ Boas, Taylor: «Conceptualizing Continuity and Change», Journal of Theoretical Politics, i9, I (2007), pp. 33-54.

${ }_{62}$ II Jornadas: op. cit.

${ }_{63}$ Una posición similar en Asad, Talal: Religion, Nation State, Secularism, Princeton, Princeton University Press, 1999. AsAD, Talal: Formations of the secular. Christianity, Islam, Modernity, Palo Alto, Stanford University Press, 2003. 
Además, la catequesis de la experiencia fomenta una búsqueda directa de la trascendencia contrastante con el tradicional predominio de la cultura canónica en la Iglesia. Asimismo, la liturgia deja de tratarse en el discurso como un instrumento sacramental y de la gracia para reseñar su papel como instrumento para la enseñanza del ciclo litúrgico y acentuar uno que realiza la unidad de la comunidad de los creyentes como aspecto central de la fe.

En suma, la secularización obligó a un trabajo pastoral integral abarcante de toda la vida de los creyentes para recuperar el universo de creencias. La aceptación de los ma fue de la mano de la construcción de una Iglesia más participativa basada en la moral y de la comunidad, lo que fomentó movimientos de base eclesiales que cambiaron la Iglesia y la participación social y política en el Tardofranquismo. La adopción de MA implicó cambios en la concepción del ser humano. A lo largo del período analizado, la idea de un ser humano práctico, que Taylor asocia con el laicismo, incrementó su aceptación, por lo que a finales del franquismo algunos catequistas aceptan que trabajo y actividad son centrales para los creyentes ${ }^{64}$. No sostenemos que la religión postconciliar sea el resultado espurio de la secularización; sólo, que la secularización redefine la religión, un hecho cultural cambiante, pero no necesariamente siempre en la misma dirección. De hecho, la crisis del modernismo reforzó, como reacción, un concepto riguroso del acceso y conocimiento del depositum fidei.

Las transformaciones llevaron necesariamente a algunos autores del final de la dictadura a responsabilizar a la Iglesia y la educación religiosa de la secularización, pedir su implicación social y cuestionar que las escuelas (nacionales) fuesen el lugar adecuado para la catequesis, argumentando que el estatus oficial de la Iglesia y una asignatura de religión confesional obligatoria dificulta la renovación y la transmisión de una fe viva. La deserción de los españoles de la Iglesia, a pesar del mantenimiento de la catequesis escolar, parece ratificar sus críticas.

${ }^{64}$ TAYLOR: op. cit. 